\title{
Revisiting the modern toolkit to optimize breast conservation surgery
}

\author{
David M. Lesniak ${ }^{1}$, Krishna B. Clough ${ }^{1}$, Brigid K. Killelea ${ }^{2}$ \\ ${ }^{1}$ Linstitut du Sein- Paris Breast Centre, Paris, France; ${ }^{2}$ Yale School of Medicine, New Haven, CT, USA \\ Correspondence to: Brigid K. Killelea, MD, MPH. Associate Professor, Surgical Oncology, Chief, Breast Surgery, Yale School of Medicine, New \\ Haven, CT 06520, USA. Email: brigid.killelea@yale.edu. \\ Provenance and Peer Review: This article was commissioned by the editorial office, Gland Surgery. The article did not undergo external peer review. \\ Comment on: Landercasper J, Bennie B, Ahmad HF, et al. Opportunities to reduce reoperations and to improve inter-facility profiling after initial \\ breast-conserving surgery for cancer. A report from the NCDB. Eur J Surg Oncol 2019;45:2026-36.
}

Submitted Dec 30, 2019. Accepted for publication Jan 09, 2020.

doi: $10.21037 /$ gs.2020.01.07

View this article at: http://dx.doi.org/10.21037/gs.2020.01.07

\section{Reoperation after lumpectomy}

For patients with early breast cancer, breast conservation therapy results in higher patient satisfaction with equivalent or improved long-term survival compared to mastectomy $(1,2)$. The risk of positive margins after lumpectomy, however, remains a problem. Reoperations after initial breast conservation surgery (BCS) often exceed 20\%, compromising aesthetic results, driving up healthcare costs, and prolonging time to adjuvant therapy for tens of thousands of women each year.

In the current study of more than 520,000 women identified from the National Cancer Database (NCDB); Landercasper et al., report an overall reoperation rate of $16.1 \%$ after BCS (3). More than 1,200 facilities were included in their analysis, of which, only 1 in 4 facilities had a reoperation rate under $10 \%$, the European quality benchmark (4). On multivariate analysis, Facility ID was the variable most significantly associated with reoperation. Notably, there was a four-fold variation in reoperation rates between facilities at the 10th and 90th percentile, a difference not explained by facility volume, lumpectomy rate or case mix (3).

With their elegant use of the NCDB, Landercasper et al., have demonstrated the true scale of this problem for the first time. Their results confirm those from McCahill et al. in 2012, who showed significant variation in postlumpectomy reoperation rates between 4 affiliated institutions (5). This earlier work found the hospital facility itself to be the most important determinant for reoperation, regardless of margin status after initial BCS. Yet, in both studies, the root cause for interfacility variation could not be delineated from the available data, suggesting important variables were left unmeasured.

Retrospective studies using large aggregate datasets with standardized variable fields are not sufficiently detailed to answer disease-specific research questions, often limiting a study's conclusions. For example, breast density was recently shown to have a significant impact on reoperation rates after lumpectomy (6), but this variable was not included in the studies by Landercasper or McCahill. Likewise, individual differences in decision-making and operative technique among breast surgeons, can cause significant variability in reoperation rates within a given facility (7), yet these factors are not captured in the aforementioned datasets.

Educating individual breast surgeons for improvement is arguably the most effective way to decrease both the overall rate of reoperations after lumpectomy, and the wide interfacility variation. Importantly, there are several methods for a surgeon to improve on this benchmark (8). Here, we revisit some of the tools to help minimize rates of reoperation after BCS.

\section{Margin guidelines}

In 2014, the Society of Surgical Oncology (SSO) and American Society for Radiation Oncology (ASTRO) published a consensus guideline for "no ink on tumor" as the new margin standard after BCS for invasive disease (9). 
Adoption of the SSO-ASTRO guideline has significantly reduced reoperation rates (10), yet over $25 \%$ of surgeons remain non-compliant with this recommendation $(11,12)$. While it is possible that low-volume, or community breast surgeons have yet to adopt this guideline, the work by Landercasper et al., may shed alternative insight. According to their analysis, women with aggressive tumor types (based on grade, receptor expression, and nodal status) were more likely to undergo a reoperation after lumpectomy (3). Interestingly, if tumor margins are the main indication for reoperation after lumpectomy, these factors should bear no influence on a surgeon's decision to return to the operating room. Ongoing efforts to educate all breast surgeons regarding this new guideline should help patients with "no ink on tumor" avoid unnecessary reoperation.

\section{Intraoperative assessment of margins}

In addition to stricter guideline adherence, a number of intra-operative tools exist to help breast surgeons reduce positive margins, which in turn, can reduce reoperations after BCS. Many of these techniques were discussed by Gray et al., in a recent systematic review (13). In terms of tumor localization, intraoperative ultrasound can reduce the rate of positive margins and reoperations after BCS. Moreover, intra-operative margin assessment may provide a cost-effective reduction in reoperation rates (13), an approach we are actively investigating.

\section{Oncoplastic surgery}

Oncoplastic surgery refers to a range of breast conservation techniques, combining wide tumor resection with immediate breast re-shaping (14). Since its inception in Europe the early 1990's, oncoplastic techniques have helped hundreds of thousands of women avoid mastectomy, and have rapidly become an important part of the armamentarium for European breast surgeons, complete with integrated training, formalized accreditation, and advanced degrees $(15,16)$. Oncoplastic techniques are especially useful for large invasive or in-situ lesions at high risk for significant deformity after lumpectomy $(17,18)$. Importantly, when compared to traditional BCS; oncoplastic surgery has consistently proven to decrease the rates of positive margins, reoperations, and local recurrence, while improving the cosmetic results for wide resections (19).

Despite a growing body of supporting evidence over the last decade; rates of oncoplastic surgery in North America lag behind those in Europe (20). A main reason is that many senior breast surgeons have no oncoplastic experience, and less than a third of the current breast surgery fellows will be exposed to oncoplastic techniques during their training (21). However, the tide is turning. In 2016, the American Society of Breast Surgeons (ASBrS) officially acknowledged the value of oncoplastic surgery by establishing an Oncoplastic Surgery Committee. In 2019, the ASBrS endorsed the European definition and classification by Clough et al. (14), while beginning to offer preliminary certification in oncoplastic techniques (22).

\section{Final thoughts}

The wide variation in reoperation rates after BCS highlights an urgent need for internal auditing and quality improvement initiatives. As the multimodal management of breast cancer is constantly evolving breast surgeons should continue to lead and innovate. Oncoplastic surgery, when used appropriately, represents an important addition to improve the quality of care for breast cancer patients. In holding themselves accountable for improvement, it is mandatory that breast surgeons incorporate all tools available to reduce the number of reoperations after lumpectomy.

\section{Acknowledgments}

Funding: None.

\section{Footnote}

Conflicts of Interest: The authors have no conflicts of interest to declare.

Ethical Statement: The authors are accountable for all aspects of the work in ensuring that questions related to the accuracy or integrity of any part of the work are appropriately investigated and resolved.

Open Access Statement: This is an Open Access article distributed in accordance with the Creative Commons Attribution-NonCommercial-NoDerivs 4.0 International License (CC BY-NC-ND 4.0), which permits the noncommercial replication and distribution of the article with the strict proviso that no changes or edits are made and the original work is properly cited (including links to both the formal publication through the relevant DOI and the license). 
See: https://creativecommons.org/licenses/by-nc-nd/4.0/.

\section{References}

1. van Maaren MC, de Munck L, de Bock GH, et al. 10 year survival after breast-conserving surgery plus radiotherapy compared with mastectomy in early breast cancer in the Netherlands: a population-based study. Lancet Oncol 2016;17:1158-70.

2. Flanagan MR, Zabor EC, Romanoff A, et al. A Comparison of Patient-Reported Outcomes After BreastConserving Surgery and Mastectomy with Implant Breast Reconstruction. Ann Surg Oncol 2019;26:3133-40.

3. Landercasper J, Bennie B, Ahmad HF, et al. Opportunities to reduce reoperations and to improve inter-facility profiling after initial breast-conserving surgery for cancer. A report from the NCDB. Eur J Surg Oncol 2019;45:2026-36.

4. Biganzoli L, Marotti L, Hart CD, et al. Quality indicators in breast cancer care: An update from the EUSOMA working group. Eur J Cancer 2017;86:59-81.

5. McCahill LE, Single RM, Aiello Bowles EJ, et al. Variability in reexcision following breast conservation surgery. JAMA 2012;307:467-75.

6. Walsh SM, Brennan SB, Zabor EC, et al. Does Breast Density Increase the Risk of Re-excision for Women with Breast Cancer Having Breast-Conservation Therapy? Ann Surg Oncol 2019;26:4246-53.

7. Valero MG, Mallory MA, Losk K, et al. Surgeon Variability and Factors Predicting for Reoperation Following Breast-Conserving Surgery. Ann Surg Oncol 2018;25:2573-8.

8. McEvoy MP, Landercasper J, Naik HR, et al. Update of the American Society of Breast Surgeons Toolbox to address the lumpectomy reoperation epidemic. Gland Surg 2018;7:536-53.

9. Moran MS, Schnitt SJ, Giuliano AE, et al. Society of Surgical Oncology-American Society for Radiation Oncology consensus guideline on margins for breastconserving surgery with whole-breast irradiation in stages I and II invasive breast cancer. J Clin Oncol 2014;32:1507-15.

10. Havel L, Naik H, Ramirez L, et al. Impact of the SSOASTRO Margin Guideline on Rates of Re-excision After Lumpectomy for Breast Cancer: A Meta-analysis. Ann Surg Oncol 2019;26:1238-44.

11. Morrow M, Abrahamse P, Hofer TP, et al. Trends in Reoperation After Initial Lumpectomy for Breast Cancer:
Addressing Overtreatment in Surgical Management. JAMA Oncol 2017;3:1352-7.

12. Landercasper J, Borgert AJ, Fayanju OM, et al. Factors Associated with Reoperation in Breast-Conserving Surgery for Cancer: A Prospective Study of American Society of Breast Surgeon Members. Ann Surg Oncol 2019;26:3321-36.

13. Gray RJ, Pockaj BA, Garvey E, et al. Intraoperative Margin Management in Breast-Conserving Surgery: A Systematic Review of the Literature. Ann Surg Oncol 2018;25:18-27.

14. Clough KB, Kaufman GJ, Nos C, et al. Improving breast cancer surgery: a classification and quadrant per quadrant atlas for oncoplastic surgery. Ann Surg Oncol 2010;17:1375-91.

15. Clough KB, Nos C, Salmon RJ, et al. Conservative treatment of breast cancers by mammaplasty and irradiation: a new approach to lower quadrant tumors. Plast Reconstr Surg 1995;96:363-70.

16. Down SK, Pereira JH, Leinster S, et al. Training the oncoplastic breast surgeon-current and future perspectives. Gland Surg 2013;2:126-7.

17. Clough KB, van la Parra RFD, Thygesen HH, et al. Longterm Results After Oncoplastic Surgery for Breast Cancer: A 10-year Follow-up. Ann Surg 2018;268:165-71.

18. van la Parra RFD, Clough KB, Lejalle-Alaeddine C, et al. Oncoplastic Level 2 Mammoplasty for Large DCIS: 5-Year Results. Ann Surg Oncol 2019;26:2459-65.

19. Losken A, Dugal CS, Styblo TM, et al. A meta-analysis comparing breast conservation therapy alone to the oncoplastic technique. Ann Plast Surg 2014;72:145-9.

20. Clough KB, Acosta-Marin V, Nos C, et al. Rates of Neoadjuvant Chemotherapy and Oncoplastic Surgery for Breast Cancer Surgery: A French National Survey. Ann Surg Oncol 2015;22:3504-11.

21. Chatterjee A, Gass J, Burke MB, et al. Results from the American Society of Breast Surgeons Oncoplastic Surgery Committee 2017 Survey: Current Practice and Future Directions. Ann Surg Oncol 2018;25:2790-4.

22. Chatterjee A, Gass J, Patel K, et al. A Consensus Definition and Classification System of Oncoplastic Surgery Developed by the American Society of Breast Surgeons. Ann Surg Oncol 2019;26:3436-44.

Cite this article as: Lesniak DM, Clough KB, Killelea BK. Revisiting the modern toolkit to optimize breast conservation surgery. Gland Surg 2020;9(2):478-480. doi: 10.21037/ gs.2020.01.07 